\title{
Imposter Syndrome among Pakistani Medical Students
}

\author{
Muhammad Atif Qureshi, ${ }^{1}$ Jamshad Taj, ${ }^{2}$ Muhammad Zahid Latif, ${ }^{3}$ Shumaila Zia, ${ }^{4}$ Muhammad \\ Rafique, ${ }^{5}$ Mohammad Akbar Chaudhry ${ }^{6}$
}

\begin{abstract}
Background: Imposter syndrome (IS) first described in 1978 is recently gaining more importance due to its long lasting, strong and detrimental implications on the Medical students as well as the institutions and society. The sufferers are competent objectively but they have a secret fear in them, that they are inadequate in the skills and knowledge and this secret will be open to others anytime. It is strongly associated with burnout phenomenon, anxiety, depression, many other psychological effects and many significant implications on medical education and training. Suffering students develop different styles of learning and find it difficult to learn through conventional or usual teaching strategies.

Objectives: This study objective was to find out the frequency of IS among Pakistani medical students.
\end{abstract}

\footnotetext{
${ }^{1}$ Professor of Medicine, Azra Naheed Medical College, Lahore

${ }^{2}$ Consultant Physician, Khafji General Hospital, Kingdom of Saudi Arabia

${ }^{3}$ Associate Professor of Community Medicine, Azra Naheed

Medical College, Lahore

${ }^{4}$ Associate Professor of Obstetrics \& Gynecology, Azra Naheed

Medical College, Lahore

${ }^{5}$ Professor of Paediatrics

Khawaja Muhammad Safdar Medical College, Sialkot

${ }^{6}$ Principal \& HOD Department of Medicine, Associate Professor of Community Medicine, Azra Naheed Medical College, Lahore
}

Date of Submission: 21-01-2017

Date of Acceptance for Publication: 07-02-2017

Conflict of Interest: None

Funding Source: None

\section{Contribution}

All Authors have contributed in Study Design, Data Collection, Data Analysis, Data Interpretation, Manuscript Writing and Approval.
Methodology: This was a cross sectional, descriptive study, conducted in a private medical college of Lahore, Pakistan in November 2016. Sampling technique was convenient non-probability type and study instrument was 08 items questionnaire. The students who answered "Yes" for five or more out of eight questions were considered positive for Imposter Syndrome.

Results: Out of 143 final year MBBS students 58.7\% were females \& $41.3 \%$ males. Sixty eight (68) students $(47.5 \%)$ were found having Imposter Syndrome according to the Young Imposter scale (YIS) used as questionnaire. Out of these $45(53.5 \%)$ were females and $23(38.9 \%)$ males.

Conclusion: Imposter syndrome or phenomenon may be present in significant frequencies and number among medical students. This may have detrimental effects on body, mind, personalities and academic as well as professional developments. Efforts should be made to find out IS/IP among students and to train both students and teachers.

Keywords: Imposter Syndrome, Burnout Phenomenon, Medical Students, Young Imposter Scale.

\section{Introduction}

The present time is era of exponential growth of knowledge. The medical knowledge is also growing enormously with each day. Estimation shows that in the year 1950, time to double the magnitude of medical knowledge was 50 years. In 2010 it was 3.5 years and expectedly by the year 2020 it will unbelievably be just 73 days. ${ }^{1}$ In this context to days medical graduates as well as medical students are under a lot of stresses to cope with this speed of knowledge growth. The students of the existing era are facing different issues related with more competition, higher expectations, 
distractions and stresses. To cope these, they devote more of their time, energies, resources, attention and motivation. These situations may lead to a well-known "Burnout Phenomenon". 2 This phenomenon is associated with absenteeism and even may lead to medical errors. ${ }^{3}$ Imposter syndrome is now a well-known entity and because of its association to burnout phenomenon, recently it is gaining popularity in literature. ${ }^{4-7}$

The psychological researchers Pauline Clance and Suzanne Imes were the first one to coin this term, "Imposter Syndrome, in 1978. They observed that some high achievers secretly have this sense that they cannot meet the expectations of others. They give the credit of their successes to the luck or chance instead of their abilities. ${ }^{8}$ The sufferers also have a fear that they will be exposed as incompetent in front of others. So a person with imposter syndrome or phenomenon feels like a fake, attributing the successes to the luck, discounting their significance. ${ }^{9}$

Students are one of the high risk groups for this syndrome. Students suffering from Imposter Syndrome develop feelings of self-doubt and have fear that they will be discovered by others as a person with intellectual fraud. As they consider themselves as less competent and intelligent than perceived by their colleagues, teachers, relatives and society. These sufferers fail to convince themselves that they are competent, skill full and have accomplished the goal by virtue of their abilities, which they actually possess ${ }^{2}$. Overall, they believe themselves to be less intelligent and competent than others perceive them to be. ${ }^{10}$ Imposter syndrome is associated with anxiety, low level of self-esteem, lack of confidence and a labile self-concept. ${ }^{11}$

Henning et al did a study in 1998 on Medical, dental, pharmacy and nursing students, and found 30 percent of these scoring as imposters. The imposter syndrome was considered as the most important predictor for generalized psychological stress. Oriel et al conducted a study on the residents of family medicine who knew that they are going through the training program which is essential for their success and concluded that almost one third had imposterism. ${ }^{12}$

Imposter syndrome has many significant implications on medical education and training. The sufferers are usually shy to initiate a conversation or speak out or volunteer answers or describe facts during a class, academic activity or even day to day candid conversations. Because of this hesitancy they develop different styles of learning and find it difficult to learn through conventional or usual teaching strategies.
This study was designed to find out the frequency of imposter syndrome among final year students of a private medical college so that special strategies may be suggested to improve the teaching and learning strategies as well as the curriculum.

\section{Methodology}

This was a cross sectional, descriptive study conducted in a private medical college of Lahore, Pakistan in November 2016. After approval from institutional Review Board, one hundred and fifty (150) final year MBBS students from both genders were enrolled in the study. Study setting was a private medical college of Lahore, Pakistan. Sampling technique was convenient non-probability type. After verbal informed consent all the students were briefly introduced to the study and were asked to complete the anonymous selfadministered printed questionnaires. The eight items, Young Imposter Scale (YIS) was used to do the dichotomous assessment of imposter syndrome, whether present or absent. ${ }^{2}$ It is in the form of questions and a student was considered positive for Imposter syndrome if he/she answered 5 or more questions as "Yes". Statistical analysis was done through SPSS Version 20 software (IBM Corporation, Armonk, NY, USA).

\section{Results}

One hundred and fifty (150) students were selected for the study and were asked to return the completed 08 items questionnaire. One hundred and forty three students returned the questionnaires, so the response rate was $95.33 \%$. Out of these 143 students 84 were females $(58.7 \%)$ and 59 males $(41.3 \%)$. The overall mean age of the respondents was $24.08 \pm 1.051$ years whereas mean age of male students was $24.05 \pm 1.121$ and of female students was $24.11 \pm 1.006$ years respectively.

Gender wise details of the answers of all the eight questions by respondents are given in the table 1 .

The students who answered "Yes" for five or more out of eight questions were considered positive for Imposter Syndrome. ${ }^{2}$ Sixty eight out of 143 students (47.5\%) answered "Yes" for five or more questions. Out of the 68 students positive for imposter syndrome $45(53.5 \%)$ were females and $23(38.9 \%)$ were males. Gender wise Young Imposter Scores are given in table 2. 
Table 1: Gender wise answers to Imposter Syndrome Questions.

\begin{tabular}{|c|c|c|c|c|}
\hline No. & Questions & $\begin{array}{l}\text { Answer } \\
\text { Yes/No }\end{array}$ & Males \% & Females \% \\
\hline \multirow{2}{*}{1} & \multirow{2}{*}{$\begin{array}{l}\text { Do you secretly worry that others will find out that you are not as } \\
\text { bright and capable as they think you are? }\end{array}$} & Yes & $26(44.1 \%)$ & $49(58.3 \%)$ \\
\hline & & No & $33(55.9 \%)$ & $35(41.7 \%)$ \\
\hline \multirow{2}{*}{2} & \multirow{2}{*}{$\begin{array}{l}\text { Do you sometimes shy away from challenges because of a } \\
\text { nagging self-doubt? }\end{array}$} & Yes & $26(44.1 \%)$ & $49(58.3 \%)$ \\
\hline & & No & $33(55.9 \%)$ & $35(41.7 \%)$ \\
\hline \multirow{2}{*}{3} & \multirow{2}{*}{$\begin{array}{l}\text { Do you tend to chalk your accomplishments up to being a fluke no } \\
\text { big deal or the fact that people just like you? }\end{array}$} & Yes & $16(27.1 \%)$ & $24(28.6 \%)$ \\
\hline & & No & $43(72.9 \%)$ & $60(71.4 \%)$ \\
\hline \multirow{2}{*}{4} & \multirow{2}{*}{$\begin{array}{l}\text { Do you hate making a mistake, being less than fully prepared or } \\
\text { not doing things perfectly? }\end{array}$} & Yes & $40(67.8 \%)$ & $58(69.0 \%)$ \\
\hline & & No & $19(32.2 \%)$ & $26(31.0 \%)$ \\
\hline \multirow{2}{*}{5} & \multirow{2}{*}{$\begin{array}{l}\text { Do you tend to feel crushed even by constructive criticism, seeing } \\
\text { it as an evidence of your ineptness? }\end{array}$} & Yes & $31(52.5 \%)$ & $58(69.0 \%)$ \\
\hline & & No & $28(47.5 \%)$ & $26(31.0 \%)$ \\
\hline \multirow{2}{*}{6} & \multirow{2}{*}{$\begin{array}{l}\text { When you do succeed, do you think, "Phew" I fooled them this } \\
\text { time but I may not be that lucky next time? }\end{array}$} & Yes & $12(20.3 \%)$ & $11(13.1 \%)$ \\
\hline & & No & $47(79.7 \%)$ & $73(86.9 \%)$ \\
\hline \multirow{2}{*}{7} & \multirow{2}{*}{$\begin{array}{l}\text { Do you believe that other people (students, colleagues, } \\
\text { competitors) are smarter and more capable than you? }\end{array}$} & Yes & $22(37.3 \%)$ & $21(25.0 \%)$ \\
\hline & & No & $37(62.7 \%)$ & $63(75.0 \%)$ \\
\hline \multirow{2}{*}{8} & \multirow{2}{*}{ Do you live in fear of being found out, discovered or un-masked? } & Yes & $25(42.4 \%)$ & $52(61.9 \%)$ \\
\hline & & No & $34(57.6 \%)$ & $32(38.1 \%)$ \\
\hline
\end{tabular}

Table 2: Gender wise answers to Imposter Syndrome Questions.

\begin{tabular}{|c|c|c|c|}
\hline & \multicolumn{2}{|c|}{ Gender } & \\
\hline Imposter Score & Male & Female & Total \\
\hline 0 & $5(8.5 \%)$ & $7(8.3 \%)$ & $12(8.4 \%)$ \\
\hline 1 & $16(27.1 \%)$ & $17(20.2 \%)$ & $33(23.1 \%)$ \\
\hline 2 & $6(10.2 \%)$ & $7(8.3 \%)$ & $13(9.1 \%)$ \\
\hline 3 & $6(10.2 \%)$ & $4(4.8 \%)$ & $10(7.0 \%)$ \\
\hline 4 & $3(5.1 \%)$ & $4(4.8 \%)$ & $7(4.9 \%)$ \\
\hline 5 & $7(11.9 \%)$ & $16(19.0 \%)$ & $23(16.1 \%)$ \\
\hline 6 & $10(16.9 \%)$ & $20(23.8 \%)$ & $30(21.0 \%)$ \\
\hline 7 & $3(5.1 \%)$ & $9(10.7 \%)$ & $12(8.4 \%)$ \\
\hline 8 & $3(5.1 \%)$ & $0(.0 \%)$ & $3(2.1 \%)$ \\
\hline
\end{tabular}

\section{Discussion}

Imposter syndrome also known as Imposter phenomenon is not new, but is recently gaining more impor- tance by researchers due to its long lasting, strong and detrimental implications on the individual sufferers as well as the departments, institutions, and society. In simplest way the sufferers are people who are competent objectively but they have a secret fear in them, that they are inadequate in the skills and knowledge and this secret will be open to others anytime. ${ }^{13}$

Regarding frequency of IS/IP, Jennifer A. Villwock and colleagues ${ }^{2}$ found in their recent study that nearly half of the female and quarter of the male American students from one medical school had Imposter syndrome. Henning et al and Oriel et al in two separate studies found that $30 \%$ and approximately one third of their student participants were suffering from Imposter Syndrome, but these studies were not recent. ${ }^{12}$ Our study showed almost similar trend, with total percentage of sufferers being $47.5 \%$. The reason for high prevalence may be due to the fact that all participants were from the final year MBBS class and they are at the verge of entering a practical life which is highly demanding and involves human lives.

The studies conducted earlier have shown mix evidence regarding the gender distribution. The impos- 
ter syndrome or imposter phenomenon was initially considered as to be predominant in high achieving women. But the subsequent studies showed that this phenomenon is also quite frequent among males, and many studies showed no significant difference in the frequencies among genders. But most studies showed females as relatively common sufferers, ${ }^{10}$ especially from younger age group. In our medical colleges, now a days, the females students are two third or close to this of the total student population. This adds to the significance of impacts of Imposter syndrome on medical education and trainings.

It is also found out that progress into senior classes or senior training years does not have any effect on imposter syndrome so if a student suffers, he/she will continue suffering this syndrome despite increase in education level, ${ }^{10}$ unless treated specially through a tailored and customized approach.

Out of all 08 questions, majority of students whether with imposter syndrome score or not, answered "Yes" for the following two questions. Ninety eight students $(68.53 \%)$ accepted that they hate making a mistake, being less than fully prepared or not doing things perfectly. As a result such students are likely to avoid challenges and even decline many opportunities where anyone is likely to make mistakes also.

More than half of the students are living with the fear of being found out, discovered or un-masked by others as incapable and not bright. Their fear is contrary to the obvious successes they have. The sufferers of IS/IP are usually perfectionist, needing everything at the best but also are afraid of the problems they expect to face in their interpersonal relations and the shame they will feel if their inadequacies will get open. $^{13}$

One hundred students $(69.93 \%)$ do not believe that other students are smarter and more capable then themselves.

IS/IP is associated with many psychological problems like depression, anxiety and mis-perceptions of self-abilities. It may act as a psychological barrier in people's careers especially of women. ${ }^{13,14}$ These complex combined feelings usually hinder in the progress in careers. ${ }^{14}$ thus understanding this phenomenon helps in identifying those who are at risk of leaving the institution, or even may leave the profession feeling they are not competent enough to cope with the institutional or professional expectations. ${ }^{5}$

Seventy five students $(52.44 \%)$ said that they shy away from challenges because they have doubt on their abilities. So they do not attribute the successes they get during their academic as well as practical life. These people are even in fear of success, as success will bring more responsibilities and expectations. They strongly feel that they are not worthy of the praise and appreciation they are receiving. At the same time they are afraid of failure, being perfectionist and always having successes in past, they cannot handle their failures. In addition they also have issues of self-esteem and cannot handle criticism and constructive feedback. Eighty nine students (62.23\%) confessed for feeling crushed even by constructive criticism, seeing it as an evidence of their ineptness. These complex feelings lead to anxiety, depression and many other personality issues. $^{13,14,16,17}$

Students are not confident about their abilities and teachers or administrations recognize the abilities of these individuals. So they give more and more responsibilities and challenges to them but they feel incompetent or not capable to cope with these, so there is again a mismatch between expectations and thus performances due to lack of confidence. They even cannot feel confident that if they have done all this in past why they can't just repeat this in future. This is because they think themselves as intellectual frauds and attribute their past successes to flukes. This conflicting situation causes a lot of stress, anxiety and fear. ${ }^{16,17}$

Finding imposter syndrome or phenomenon in medical students who are close to the completion of their student life can predict those at risk of facing difficulty in future during practical and professional lives. This predictive value has brought "IS" in focus of research recently. One reason may be its strong association with "burnout phenomenon" and thus increasing number of quitting, and suicides in campuses. So many institutions have started developing intensive programs for help to these IS students. ${ }^{2}$ These programs help students to find out IS/IP tendencies, and programs to focus on supporting such students. Many institutions imposter programs are part of their orientation activities. These programs help students finding whether they have the tendency or not and if yes, to join such programs. Workshops and activities may be developed to promote multicultural interactions, confidence building, success defining and strength identifycations, dealing with failures and absorbing and utilizing constructive feedbacks and criticism. Students may be trained to understand perfectionism and how to set expectations for them which are more reasonable and achi-evable. $^{18}$

Similarly many programs should be developed for the faculty, staff and administration. They should be 
trained to identify the needs of such students and providing those help to cope with the problem. Workshops on mentoring, finding ways for confidence boosting, constructive structured feedback, mentor selection, clearly defining institutional expectations, ${ }^{16}$ developing stress busting activities and providing peer and workplace social support groups ${ }^{19}$ should be organized regularly. The publication "Beating the Imposter Syndrome" from the Centre for Creative Leadership published in 2014 may help developing such workshops especially at orientation levels. ${ }^{2}$

There are few limitations of this study. This was a survey based study with convenient non-probability sampling in only one private medical college. Sample size was also relatively small. It would have been much better if done at multiple centers with a significantly large number of students. Significant associations may change with a larger sample. But this study is an effort to bring this important entity in light so that other researches can do more research on different aspects of imposter syndrome.

\section{Conclusion}

Imposter syndrome or phenomenon is present in significant frequencies and number among medical students. This may have detrimental effects on body, mind, personalities and academic as well as professional developments. Efforts should be made to find out IS/IP among students and to train both students and teachers.

\section{References}

1. Densen P. Challenges and opportunities facing medical education. Transactions of the American Clinical and Climatological Association, 2011; 122: 48.

2. Villwock JA, Sobin LB, Koester LA, Harris TM. Impostor syndrome and burnout among American medical students: a pilot study. International Journal of Medical Education, 2016; 7: 364 .

3. McCray LW, Cronholm PF, Bogner HR, Gallo JJ, Neill RA. Resident physician burnout: is there hope? Fam Med. 2008; 40: 626-632.

4. Pajares F. Toward a Positive Psychology of Academic Motivation. J Educ Res. 2001; 95: 27-35.

5. Cozzarelli $\mathrm{C}$ and Major B. Exploring the Validity of the
Impostor Phenomenon. J Soc Clin Psychol. 1990; 9: 401-417.

6. Cohen MJ, Kay A, Youakim JM, Balaicuis JM, Balacius JM. Identity transformation in medical students. Am J Psychoanal. 2009; 69: 43-52.

7. Kolligian J, Sternberg RJ. Perceived fraudulence in young adults: is there an "imposter syndrome"? J Pers Assess. 1991; 56: 308-326.

8. Sherman RO. Imposter syndrome: When you feel like you're faking it. Am Nurse Today, 2013; 8 (5): 57-8.

9. Simmons D. Impostor Syndrome, a Reparative History. Engaging Science, Technology, and Society, 2016; 1; 2: 106-27.

10. Legassie J, Zibrowski EM, Goldszmidt MA. Measuring resident well-being: impostorism and burnout syndrome in residency. J Gen Intern Med. 2008; 23: 1090-1094.

11. Gibson-Beverly G, Schwartz JR. Attachment, entitlement, and the impostor phenomenon in female graduate students. Journal of College Counseling. 2008. 22; 11 (2): 119-33.

12. Oriel K, Plane MB, Mundt M. Family medicine residents and the impostor phenomenon. Fam Med. 2004; 36: 248-252.

13. Jostl G, Bergsmann E, Luftenegger M, Schober B, Spiel C. When Will They Blow My Cover? The Impostor Phenomenon Among Austrian Doctoral Students. Zeitschrift Fur Psychologie-Journal of Psychology. 2012; 220 (2): 109-20.

14. Clark MM, Vardeman MK, Barba MS. Perceived inadequacy: A study of the imposter phenomenon among college and research librarians. College \& Research Libraries, 2012; 19: 112-423.

15. Parkman A. The Imposter Phenomenon in Higher Education: Incidence and Impact. Journal of Higher Education Theory and Practice, 2016; 16 (1): 51.

16. Hutchins HM. Outing the imposter: A study exploring imposter phenomenon among higher education faculty. New Horizons in Adult Education and Human Resource Development, 2015; 27 (2): 3-12.

17. Sakulku J, Alexander J. The impostor phenomenon. International Journal of Behavioral Science (IJBS) 2011: 6 (1).

18. Cokley K, McClain S, Enciso A, Martinez M. An examination of the impact of minority status stress and impostor feelings on the mental health of diverse ethnic minority college students. Journal of Multicultural Counseling and Development, 2013; 41 (2): 82-95.

19. Vergauwe J, Wille B, Feys M, De Fruyt F, Anseel F. Fear of being exposed: the trait-relatedness of the impostor phenomenon and its relevance in the work context. Journal of Business and Psychology, 2015; 30 (3): 56581. 